\section{Maternity Care Today}

Malla DS

Department of Obs/Gyn, Nepal Army Institute of Health Sciences

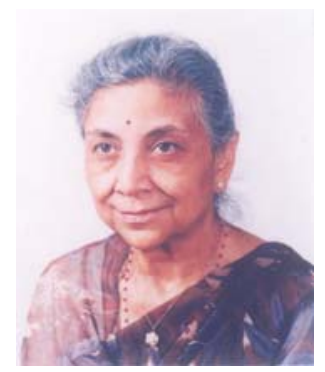

at a glance". ${ }^{3}$ This format aids in clinical governance and can be employed to monitor organizational performance.

Model of care cannot be considered in isolation, as the care mix and available workforce mix will impact upon what is available and appropriate for the woman being cared for. Talking of care, majority of pregnancy and child birth go through a normal process, the availability of a midwife who is a specialist of normal maternity care service will enhance the capacity of the workforce. Mr Ban Ki- moon, Secretary General of the United Nation writes in The State of The World's Midwifery 2011 “Using fresh data, information and analysis, the report identifies common challenges within and among countries while highlighting promising approaches to strengthen midwifery services around the world". It adds on "Ensuring that every woman and her newborn have access to quality midwifery services demands that we take bold steps to build on what we have achieved so far across communities, countries, regions and the world". ${ }^{4}$

To conclude let me say that "A life-course approach to women's health care should be adopted utilizing every interaction a woman has with the health service, in particular Maternity Service, irrespective of age, to promote health and lifestyle rather than the firefight against disease and ill health". Time demands radical and appropriate shake-up of Women's health services promoting prevention rather than intervention.

\section{REFERENCES}

1. Mahmood T, Owen P, Arulkumaran S, Dhillon C. Models of care in maternity service. $1^{\text {st }}$ ed. London:RCOG;2010.

2. http://www.rcog.org.uk/high-quality-womens-health-care

3. Royal College of Obstetricians and Gynaecologist . Maternity dashboard: Clinical performance and governance gcorecard. Good Practice No 7 . London:RCOG;2008.

4. The State of The World's Midwifery 2011 www. stateoftheworldsmidwifery.com

\section{CORRESPONDENCE}

Prof. Dibya Shree Malla, FRCOG

Shree Birendra Hospital, Chhauni, Kathmandu

Mobile : 9841283074

Email : dibyanm@healthnet.org.np 